University of Nebraska - Lincoln

DigitalCommons@University of Nebraska - Lincoln

\title{
On Diurnal Riparian Zone Groundwater-Level and Streamflow Fluctuations
}

Jozsef Szilagyi

University of Nebraska - Lincoln, jszilagyi1@unl.edu

Zoltan Gribovszki

Budapest University of Technology and Economics

Peter Kalicz

Institute of Geomatics and Civil Engineering

Mihaly Kucsara

Institute of Geomatics and Civil Engineering

Follow this and additional works at: https://digitalcommons.unl.edu/natrespapers

Part of the Natural Resources and Conservation Commons, Natural Resources Management and Policy Commons, and the Other Environmental Sciences Commons

Szilagyi, Jozsef; Gribovszki, Zoltan; Kalicz, Peter; and Kucsara, Mihaly, "On Diurnal Riparian Zone Groundwater-Level and Streamflow Fluctuations" (2007). Papers in Natural Resources. 955.

https://digitalcommons.unl.edu/natrespapers/955

This Article is brought to you for free and open access by the Natural Resources, School of at DigitalCommons@University of Nebraska - Lincoln. It has been accepted for inclusion in Papers in Natural Resources by an authorized administrator of DigitalCommons@University of Nebraska - Lincoln. 


\title{
On diurnal riparian zone groundwater-level and streamflow fluctuations
}

\author{
József Szilágyi ${ }^{a, b, *}$, Zoltán Gribovszki ${ }^{a, c}$, Péter Kalicz ${ }^{c}$, Mihály Kucsara ${ }^{c}$
}

a Department of Hydraulic and Water Resources Engineering, Budapest University of Technology and Economics, Budapest, $H-1111$, Hungary

b School of Natural Resources, University of Nebraska-Lincoln, 113, Nebraska Hall, Lincoln, NE 68583, USA

c Institute of Geomatics and Civil Engineering, University of Western Hungary, Sopron, H-9400, Hungary

Received 30 January 2007; received in revised form 24 August 2007; accepted 6 September 2007

KEYWORDS

Riparian zone;

Diurnal fluctuations;

Groundwater-level;

Streamflow;

Riparian ET
Summary Gribovszki et al. (Gribovszki, Z., Kalicz, P., Szilagyi, J., Kucsara, M., 2008. Riparian zone evapotranspiration estimation from diurnal groundwater-level fluctuations. J. Hydrol.) recently reported a peculiar phase-shift in diurnal streamflow and riparian zone groundwater-level fluctuations during streamflow recession for a small forested watershed. Employing high-frequency $(10 \mathrm{~min})$ groundwater-level and streamflow measurements in a wooded riparian zone of a gaining stream they demonstrated that groundwater-level changes lagged behind that of streamflow changes by about $1-1.5 \mathrm{~h}$. To check the validity of their claim, a 2D finite element numerical model of the coupled system of vadose and saturated zones was employed with diurnal fluctuations in evapotranspiration. The model successfully reproduced the reported phase-shift and produced diurnal groundwater and streamflow fluctuations similar in their characteristics to what was reported. This finding demonstrates that by observing a similar phase-shift in diurnal fluctuations between high-frequency streamflow rate (or stream stage) and groundwater-level measurements during recession flow conditions, does not, in itself, indicate that the stream section is a losing one.

(c) 2007 Elsevier B.V. All rights reserved.

\footnotetext{
* Corresponding author. Address: School of Natural Resources, University of Nebraska-Lincoln, 113, Nebraska Hall, Lincoln, NE 68583, USA. Tel.: +1 361463 1885; fax: +1 3614631879 .

E-mail address: jszilagyi1@unl.edu (J. Szilágyi).
}

\section{Introduction}

Recently Gribovszki et al. (2008) reported an unexpected phase-shift in diurnal fluctuations of riparian zone groundwater-levels and streamflow, i.e. groundwater-levels are lagging behind streamflow rates by about $1-1.5 \mathrm{~h}$. Their observation was based on high-frequency readings $(10 \mathrm{~min})$ of a pressure transducer placed in a groundwater 
well (having a diameter of $6.3 \mathrm{~cm}$ ) situated about $9 \mathrm{~m}$ from a perennial stream of a hilly, forest-covered (i.e. alder [Alnus glutinosa] in the riparian zone) experimental watershed (called Hidegvíz-völgy, with a drainage area of $6 \mathrm{~km}^{2}$ ) at the north-western border of Hungary. Flow measurements were taken by a weir (combined with a pressure transducer to determine the precise position of the water level in the stilling basin) with the same frequency as groundwater-level readings over a period of one year. For more information on site description, please, refer to Gribovszki et al. (2008).

As typically the case, diurnal fluctuations are visible only on the falling limb of the hydrographs during recession flow periods (see references in Gribovszki et al. (2008)). The stream section in question is a gaining one (based on groundwater profile measurements in the riparian zone), although occurrences of induced recharge, when the stream feeds the saturated zone, during intensive evapotranspiration (ET) events in the summer may not be ruled out completely. As it is shown below, this potential induced recharge, however, may not be the cause of the reported unusual phase-shift.

An intensive literature review lately was unsuccessful in finding any mentioning of this "anomalous" phase-shift between streamflow and riparian zone groundwater-levels. It appears anomalous because as ET increases during the day, the phreatophyte vegetation consumes ever increasing amounts of water from the vadose and saturated zones, thus depressing the groundwater-table. Because some of the water that previously supplied the stream now is consumed by the vegetation, the water "pumped out" by ET will entail a decrease in the groundwater-flow rate directed toward the stream. The apparent anomaly occurs when this decrease in groundwater-flow toward the stream (measured as stream baseflow) precedes that of the groundwater-level as is seen in Fig. 1. The same is observed when ET starts to decrease in the afternoon: the streamflow increase is observed sooner in time than the corresponding rise in groundwater-levels (Fig. 1).

The question is whether this anomaly that was probably first reported by Gribovszki et al. (2008) in the literature

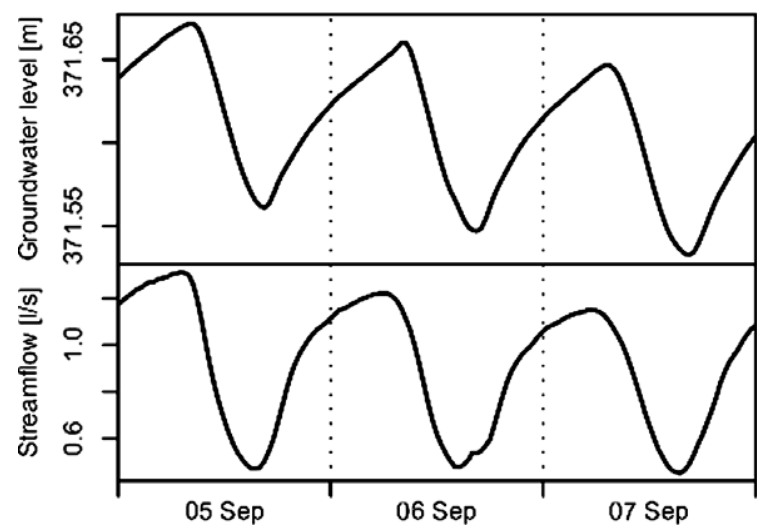

Figure 1 Observed diurnal fluctuations in the riparian zone groundwater-level and streamflow values at the Hidegvíz-völgy experimental catchment of north-western Hungary (from Gribovszki et al., 2008). is real or just a result of possible inappropriate data handling and manipulation, such as the smoothing of the $10 \mathrm{~min}$ values of both the groundwater-level and streamflow measurements.

\section{Model description, results and discussion}

To test the validity of the reported phase-shift between streamflow rate and groundwater-level, an adaptive, finite element 2D numerical model was employed for integrating the extended Richards equation (Lam et al., 1987) in a vertical plane

$\frac{\partial}{\partial x}\left[K(\Psi) \frac{\partial h}{\partial x}\right]+\frac{\partial}{\partial y}\left[K(\Psi) \frac{\partial h}{\partial y}\right]+s=m \gamma \frac{\partial h}{\partial t}$

where $K$ is the hydraulic conductivity (a function of the suction/pressure head, $\Psi$ ); $h$ is the total hydraulic head; $m$ is the slope of the water retention curve which becomes the coefficient of volume change in the saturated zone; $s$ is a source/sink term; $\gamma$ is the unit weight of water; and $x, y$, and $t$ denote the horizontal, vertical and temporal coordinates, respectively.

The simulations started with a horizontal groundwaterlevel $(0.6 \mathrm{~m}$ above the horizontal impervious layer) at $t=0$, equaling the water level in the adjacent fully incised (i.e. channel bottom is at the impervious layer) stream (Fig. 2). Stream level is then suddenly dropped to a fixed elevation (i.e. to $0.1 \mathrm{~m}$ ) for $t>0$ to induce drawdown of the aquifer. Aquifer geometry is similar to what was reported by Gribovszki et al. (2008) for their measurement site. The aquifer width $(B)$ is $20 \mathrm{~m}$, the mean aquifer thickness is $2 \mathrm{~m}$, the ground surface has a gentle (1:10) slope, the impermeable layer is horizontal and the stream is fully incised (Fig. 2). Prescribed aquifer material properties are listed in Table 1. The saturated hydraulic conductivity, $K_{\mathrm{s}}$, value $(0.67 \mathrm{~m} / \mathrm{d}$, from Szilagyi $(2003,2004))$ of the model aquifer is close to the slug-test-derived median value $(1.55 \mathrm{~m} / \mathrm{d})$ reported by Gribovszki et al. (2008), especially when one considers the possible wide range (i.e. a magnitude of order 10) for the $K_{\mathrm{s}}$ values.

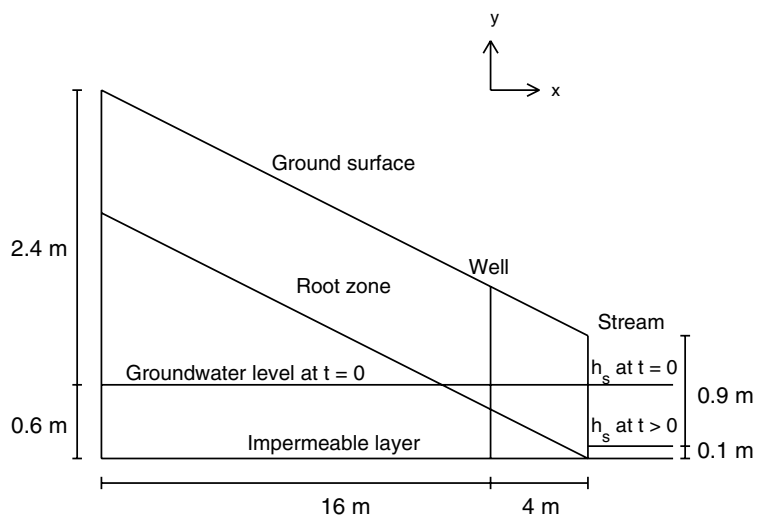

Figure 2 Schematic vertical cross-section of the aquifer employed in the numerical model. The left-side of the aquifer represents no-flow conditions, and the fully incised stream $\left(h_{\mathrm{s}}\right.$ is stream stage) is on the right-side of the aquifer. 
Table 1 Hydraulic properties of the model aquifer (after Campbell (1974) and Clapp and Hornberger (1978))

\begin{tabular}{|c|c|c|}
\hline $\begin{array}{l}\text { Hydraulic } \\
\text { property }\end{array}$ & Value/equation & Explanation \\
\hline$\varphi[-]$ & 0.45 & $\varphi-$ total porosity \\
\hline$K_{\mathrm{s}}[\mathrm{m} / \mathrm{d}]$ & 0.67 & $\begin{array}{l}K_{\mathrm{s}}-\text { saturated hydraulic } \\
\text { conductivity }\end{array}$ \\
\hline$\Psi_{\mathrm{ae}}[\mathrm{kPa}]$ & 4.68 & $\Psi_{\mathrm{ae}}-$ air-entry pressure \\
\hline$\Psi(\Theta)$ & $\left|\Psi_{\mathrm{ae}}\right|(\varphi / \Theta)^{\mathrm{b}}$ & $\begin{array}{l}\Theta-\text { volumetric water } \\
\text { content }[-]\end{array}$ \\
\hline$K(\Theta)$ & $K_{s}(\Theta / \varphi)^{2 b+3}$ & $\begin{array}{l}\mathrm{b}(=5.39)-\text { pore size } \\
\text { distribution index }\end{array}$ \\
\hline
\end{tabular}

The $1 \mathrm{~m}$ thick root zone considered in the model starts at the surface and lies parallel with the sloping ground surface. Water used by the riparian vegetation for its transpirational need is represented by the term $s$ (now a sink for groundwater and soil moisture, respectively, depending whether the root zone is saturated or not) in (1), restricted to the root zone only. Diurnal water use fluctuation is described by

$s=-\frac{x}{B} c \sin ^{2}(\pi t / 12), \quad 0 \leqslant \bmod (t / 24)<12$

$s=0, \quad 12 \leqslant \bmod (t / 24)<24$

where $c\left(=2.16 \times 10^{-2} \mathrm{~d}^{-1}\right)$ is a constant and mod is the modulus of division with time measured in hours. Eq. (2) ensures that for one-half of the day water uptake by the vegetation from the root zone is zero, and follows a sine-like curve for the other half, taking only positive values. Note that in Eq. (2) water uptake intensity from the root zone linearly increases with the proximity of the stream. It meant to replicate general tendencies showing that by an increase in the depth to the groundwater with increasing elevation of the ground surface, vegetation tends to use a decreasing amount of water from the soil. The prescribed value of $C$ yields a daily mean ET of $5.4 \mathrm{~mm}$ at $x=B$, which is close to the growing season daily mean ET value reported by Gribovszki et al. (2008).

The fixed value of the stream level for $t>0$ in the model allowed for possible induced recharge during the drawdown. Groundwater-level in the model (its position determined by $h=y$ ) was monitored along a vertical (denoted by "well"), set $4 \mathrm{~m}$ from the stream (Fig. 2). Aquifer drainage rate was obtained by integrating the horizontal component of the Darcy-flux vectors at $x=B$ along the vertical stream bank.

Fig. 3 displays the resulting aquifer outflow rates together with the groundwater elevation in the 'well' for about the last 4 days of the 8-day long recession period modeled. The diurnal fluctuations in both the outflow rates and groundwater-levels are clearly visible and in shape are similar to what was observed by Gribovszki et al. (2008) in Fig. 1. The groundwater-level fluctuations, both modeled and observed, are marked by straighter line segments than that of the flowrate values. The rising limbs of the flowrate hydrographs, both modeled and observed, are significantly more rounded than the corresponding groundwater-level curve sections. The amplitude of the observed groundwater-level fluctuations is about twice as large though as that of the simulated one, partly because the model aquifer has larger porosity than the experimental catchment. The general decreasing trend in both the outflow and water level values is stronger in the model than what is observed, due to the somewhat artificial initial condition of a flat groundwater-level applied in the model which results in a subsequent intense drainage.

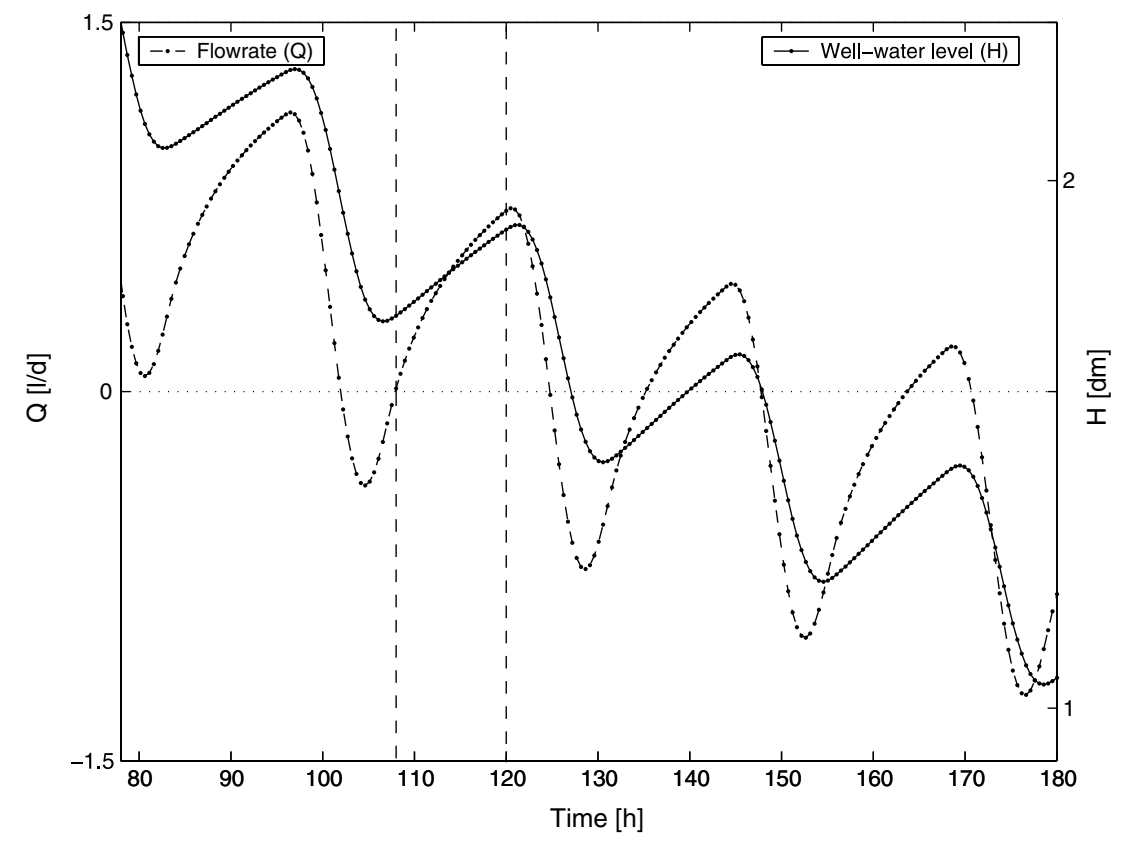

Figure 3 Modeled aquifer outflow, $Q$, and well-water level, $H$, time series in the second part of the 8-day drawdown with a constant stream-water level of $0.1 \mathrm{~m}$ for $t>0$. The first vertical line denotes the end of the previous ET cycle at hour 108 and the second one denotes the start of the following one at hour 120 , for easier interpretation. 
The most interesting feature of the model results is that the reported $1-1.5 \mathrm{~h}$ phase-shift, observable in Fig. 1 , is also recaptured in Fig. 3 to a large extent. Clearly, modeled groundwater-level response to ET fluctuations lags behind that of the modeled flowrate. The lag is about $60 \mathrm{~min}$ (the time period between subsequent data points in Fig. 3 is $30 \mathrm{~min}$ ) for the peaks, and about twice as large, $120 \mathrm{~min}$, for the troughs. On day 5 and onward of the modeled drawdown, aquifer outflow becomes negative periodically, indicating induced recharge from the stream. Note, however, that the phase-shift is already present on day 4 when no induced recharge takes place between the stream and the adjacent aquifer, indicating that induced recharge is not the cause of the "anomalous" phase-shift.

No clear relationship could be found between the magnitude of the modeled phase-shift and the geometrical characteristics of the aquifer in terms of the location and width of the root zone, the shape of the aquifer, the initial groundwater-level, or the constant stream-water level. Similarly, the rate of ET, whether it increases with the proximity of the stream or not or whether the left-side of the aquifer represents no-flow or flow-through conditions had no clear effect on the phase-shift either. Neither did an almost 10 -fold increase in the value (from $1.48 \times 10^{-4} \mathrm{kPa}^{-1}$ ) of the coefficient of volume change $(m)$ within the saturated zone. Note that the numerical integration of Eq. (1)

Table 2 Characteristic time-shift between modeled groundwater-level and flow extrema as a function of the distance $(L)$ between the "well" and the stream

\begin{tabular}{llllll}
\hline$L(\mathrm{~m})$ & 1 & 2 & 4 & 6 & 10 \\
\hline Time-shift $(\mathrm{h})$ & 0.5 & 0.75 & 1.5 & 1.75 & 1.75 \\
\hline
\end{tabular}

requires a value different from zero for $m$ even in the saturated zone, thus, making the unconfined aquifer elastic. In theory, elasticity could explain the observed phase-shift, or at least its tendencies, was: (a) the prescribed value not so small, and; (b) the saturated zone modeled not so shallow. In certain cases (e.g. horizontal ground surface with thin root zone completely within the saturated zone) the phase-shift in the peak values disappeared, but not in case of the minima. Also, it never happened that groundwater-table response would have preceded the flow response. The only variable that had a clear effect on the modeled phase-shift, however, was the distance $(L)$ of the "observation well" from the stream. Table 2 displays the time-shift as a function of $L$ within the current model setup. As seen, it increases from $30 \mathrm{~min}(L=1 \mathrm{~m})$ to $1.75 \mathrm{~h}(L \geqslant 6 \mathrm{~m})$.

The phase-shift can be conceptualized the following way. When water removal via ET from the aquifer starts to decline, the saturated zone is expected to respond by starting to bounce back from its depressed state (due to a spatially changing "local" hydraulic gradient along the groundwater-surface) and reach its normal drawdown curve. This, however, is being counteracted by a simultaneous increase in the overall hydraulic gradient and thus a quick increase in the outflow rate leading to further depressing the groundwater profile for a while. Observations of Gribovszki et al. (2008) and the present model results indicate that at least for a short period (i.e. $1-1.5 \mathrm{~h}$ ) the temporary increase in the overall hydraulic gradient is indeed more efficient in water transport than the "local" ones and thus it temporarily overcomes the expected adjustment of the groundwater surface. Soon, however, the "local" head gradients smooth out any irregularities in the drawdown profile, which may involve an increase in the groundwater-surface elevation.

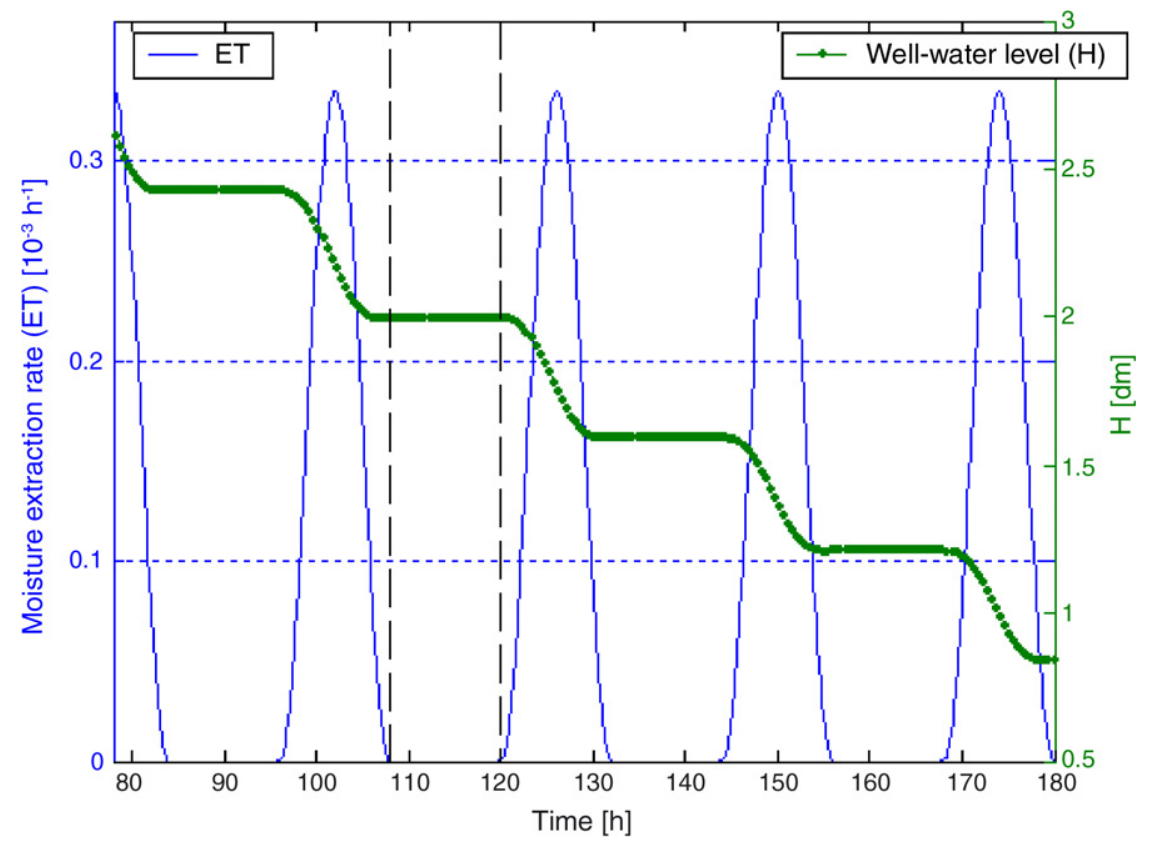

Figure 4 Spatially uniform moisture extraction rate that corresponds to a daily ET rate of $2 \mathrm{mmd}^{-1}$ from a flat, $1 \mathrm{~m}$ thick aquifer with a root zone of $1 \mathrm{~m}$ in depth and initial water level of $0.6 \mathrm{~m}$. The dots denote the elevation of the groundwater-surface at the "well" $4 \mathrm{~m}$ from the right edge. The aquifer now has no-flow boundaries at either side. 


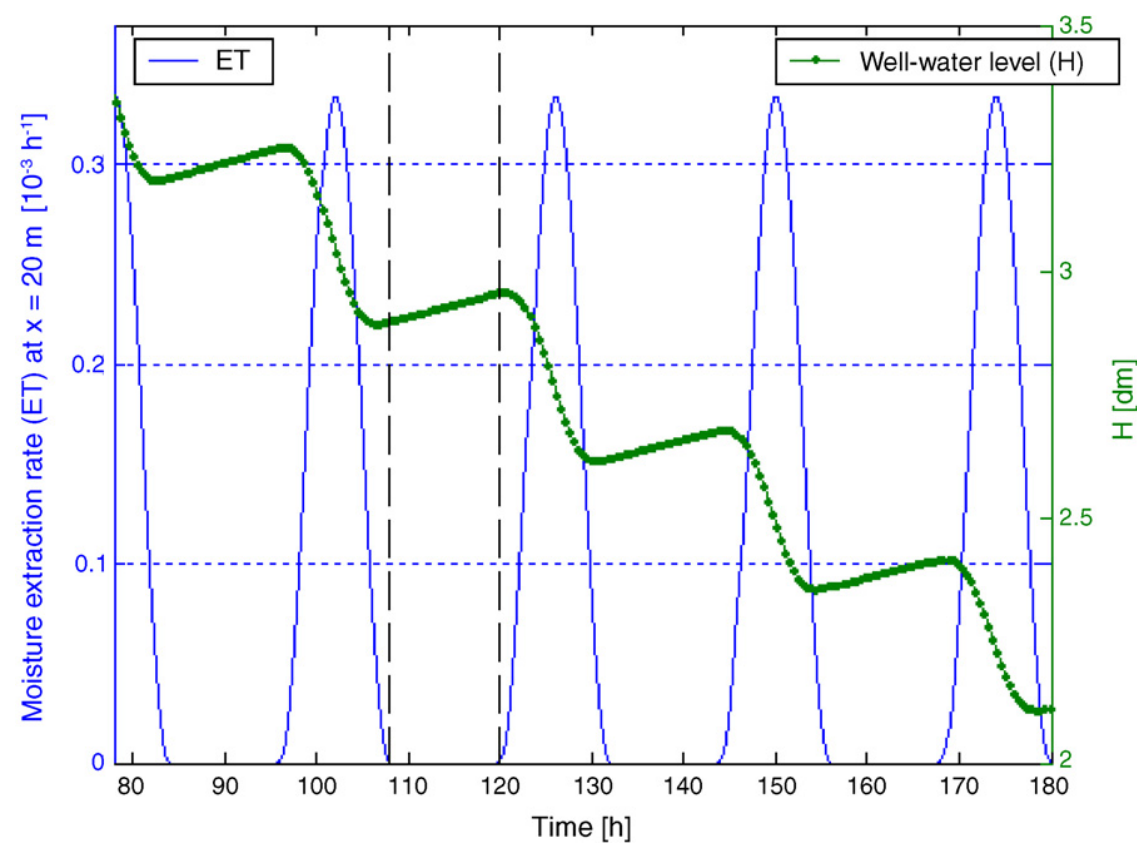

Figure 5 Same as Fig. 4, except that moisture extraction now varies according to Eq. (2) with $c=8 \times 10^{-3} \mathrm{~d}^{-1}$.

To illustrate the importance of the "local" hydraulic gradient, two further numerical experiments were performed. In the first one, water removal from the aquifer was spatially homogeneous, although following the same daily rhythm as before. The aquifer was impervious at either side, so it acted as a "sandbox", water from its initial $0.6 \mathrm{~m}$ thick saturated zone could only leave through the root zone. As displayed in Fig. 4, no bouncing-back of the groundwatersurface after each ET period is observed in the "well" due exactly to a lack of spatially changing "local" hydraulic gradient along the water surface. When, however, the system becomes disturbed, via a spatially changing ET rate similar to Eq. (2), it will respond to attain its typical drawdown curve (which is now horizontal) by such "local" readjustment, which now may involve an immediate increase in the groundwater-surface at locations where actual groundwater-surface elevation is below the drawdown curve of a spatially homogeneous ET rate case, as demonstrated in Fig. 5.

The same is true for the opposite process, when water removal through ET starts to intensify. The saturated zone is expected to respond to this growing demand for water by a decrease in its thickness, however, overall gradientchange will lead to an immediate cutting back on its outflow rate (or similarly lead to boosting inflow during induced recharge events). Again, saturated thickness, and with it, storage, may still continue to increase for a while, provided the change in the drainage rate is sufficiently large enough to meet the elevated demand in ET combined with this continued temporary storage growth.
As a practical consequence of the observed and modeled phase-shift between diurnal riparian zone aquifer drainage and groundwater-level fluctuations is that at such a temporal scale and when the process is driven by fluctuations in riparian zone ET rates, a lagging groundwater-level response in comparison with stream-water fluctuations, both of sufficiently high temporal resolution, is not in itself a decisive indicator of any induced recharge and/or of the presence of a temporarily or permanently losing stream section.

\section{References}

Campbell, G.S., 1974. A simple method for determining unsaturated conductivity from moisture retention data. Soil Sci. 117, 311314.

Clapp, R.B., Hornberger, G.M., 1978. Empirical equations for some soil hydraulic properties. Water Resour. Res. 14, 601-604.

Gribovszki, Z., Kalicz, P., Szilagyi, J., Kucsara, M., 2008. Riparian zone evapotranspiration estimation from diurnal groundwaterlevel fluctuations. J. Hydrol. 349, 6-17.

Lam, L., Fredlund, D.G., Barbour, S.L., 1987. Transient seepage model for saturated-unsaturated soil systems: a geotechnical engineering approach. Can. Geotech. J. 24, 565-580.

Szilagyi, J., 2003. Sensitivity analysis of aquifer parameter estimations based on the Laplace equation with linearized boundary conditions. Water Resour. Res. 39 (6) (Art. \#1156).

Szilagyi, J., 2004. Vadose zone influences on aquifer parameter estimates of saturated zone hydraulic theory. J. Hydrol. 286, 78-86. 